\title{
FORMAÇÃO CONTINUADA: FUNDAMENTO DA GESTÃO DO CAPITAL HUMANO EM PERSPECTIVA PÚBLICA
}

\author{
Roberson Polimeni Goes ${ }^{1}$
}

\begin{abstract}
RESUMO
O presente artigo tem como proposta a apresentação de uma experiência pública no setor gestão de capital humano por meio da formação continuada na área da educação a fim de demonstrar a preocupação do Estado com a formação profissional de seus colaboradores bem como, comprovar que o setor público também possui meios de implementação de uma educação corporativa. O programa apresentado foi idealizado e é aplicado pela Secretaria de Educação do Estado do Paraná com o objetivo de proporcionar ao professor da educação básica da rede pública estadual suporte teórico e metodológico para o redimensionamento de sua prática educativa. $O$ estudo da proposta foi realizado por meio de leituras de documentos oficiais.
\end{abstract}

Palavras-chave: Formação continuada. Gestão de capital humano. Estado do Paraná

${ }^{1}$ Mestre, e-mail: roberson.goes@pr.senai.br 


\section{INTRODUÇÃO}

Muitos são os estudos que demonstram que o Capital Humano, conjunto de investimentos destinados à formação educacional e profissional de determinada população, tornou-se uma das principais fontes de inovação organizacional tanto na esfera privada quanto na pública.

O Capital Humano desempenha papel fundamental em um sistema onde as expressões de ordem são competitividade global, ambiente de qualidade total e busca incessante pela liderança.

Ao visualizar este cenário e ao somar a ele as mudanças significativas e acentuadas do mundo do trabalho na sociedade contemporânea, é clara a necessidade de investimento das organizações privadas e, porque não, públicas, na educação corporativa de seus colaboradores.

As mudanças que as empresas necessitam fazer para manterem-se competitivas no mercado são de ordem bastante frequente. Contudo, o que se observa é que mesmo com toda atitude pró-ativa, os resultados estão aquém do esperado.

A preocupação observada no setor privado é a mesma vislumbrada pelo setor público, que apesar de não ter o perfil competitivo do setor privado, apresenta uma preocupação bastante legítima com a gestão de seu Capital Humano.

Com este espaço aberto, surge uma nova tendência: a organização orientada para o aprendizado. Estamos entrando na era do aprendizado organizacional. O setor público e o privado brasileiro começam a perceber a necessidade de se repensar seus tradicionais métodos de treinamento, aperfeiçoamento e desenvolvimento que, diante da atual conjuntura, precisam aperfeiçoar a formação necessária para o bom desempenho esperado.

Hoje, mais do que nunca, faz-se essencial a adoção de uma postura voltada à formação continuada de todos os colaboradores de uma organização: funcionários, clientes, fornecedores.

Mundim (2002, p. 63) expõe que "[...] a educação continuada consiste em um processo de aperfeiçoamento e atualização de conhecimentos, visando melhorar a capacitação técnica e cultural do profissional". A educação corporativa, como prática coordenada de gestão de pessoas e de gestão do conhecimento tendo como orientação a estratégia de longo prazo de uma organização e mais do que treinamento empresarial ou qualificação de mão-de-obra, articula coerentemente as competências individuais e organizacionais no contexto mais amplo da empresa e objetiva fundamentalmente a atualização técnica, cultural e profissional do indivíduo e, consequentemente, a otimização da competência e da eficiência no exercício da profissão. 
Diante de todas as mudanças pelas quais passam não só o mercado de trabalho, mas toda a sociedade contemporânea faz-se iminente a adoção de um modelo de formação continuada que permute o treinamento tradicional, estanque e finito, por uma forma de educação que seja contínua e que permita a aquisição de novas qualificações e competências durante toda a vida profissional, bem como, que direcione para o indivíduo a responsabilidade pelo aprendizado dessas novas qualificações.

O mercado de trabalho público e privado não tem mais espaço para o despreparo. O profissional deste milênio deve saber articular habilidades (capacidade, técnica, talento), conhecimentos (informações, procedimentos, fatos e conceitos) e atitudes (valores, princípios, opiniões e percepções). Pode-se dizer que esse articular resumese em saber, saber fazer, querer fazer, poder fazer. A mudança requer vontade interior e comprometimento das pessoas, o que resulta de relações de trabalho baseadas na confiança e no respeito que dignifica e valoriza o ser humano. Muito da valorização decorre da postura profissional adotada que, por sua vez, decorre de uma boa formação básica e continuada.

O presente artigo toma para si, a partir deste ponto, a tentativa de demonstrar que um dos quesitos de extrema importância na ordem qualitativa de uma empresa é a Gestão Estratégica dos Recursos Humanos por meio da formação continuada.

Esse requisito é tão fundamental que vem sendo desenvolvido em toda e qualquer área da atividade humana e este artigo apresentará uma tentativa pública de aplicação do processo, sob o ponto de vista deste artigo, de educação corporativa.

A iniciativa de se apresentar uma análise da proposta pública surgiu da observação empírica de um projeto desenvolvido pelo governo do Estado do Paraná, por meio da Secretaria de Estado da Educação (SEED).

O artigo justifica-se porque toda iniciativa de gestão do Capital Humano proveniente do órgão responsável pela formação de cidadãos e futuros profissionais que povoarão o mercado de trabalho paranaense e brasileiro precisa ser levada em consideração.

\section{PROGRAMA DE DESENVOLVIMENTO EDUCACIONAL DA SECRETARIA DE ESTADO DA EDUCAÇÃO DO PARANÁ - PDE/PR}

A Secretaria de Estado da Educação, em parceria com a Secretaria de Estado da Ciência, Tecnologia e Ensino Superior, institui o Programa de Desenvolvimento Educacional (PDE), como uma política educacional inovadora de Formação Continuada dos professores da rede pública estadual. O PDE propõe um conjunto de atividades organicamente articuladas, definidas a partir das necessidades da Educação Básica, e que busca no Ensino Superior a contribuição solidária e compatível com o nível de qualidade desejado para a educação pública no Estado do Paraná. 
Idealizado durante a elaboração do Plano de Carreira do Magistério (Lei Complementar n. 103, de 15 de março de 2004), lei essa que institui e dispõe sobre o Plano de Carreira do Professor da Rede Estadual de Educação Básica do Paraná, a partir das reuniões conjuntas entre os gestores da Secretaria de Educação do Estado do Paraná (SEED) e os representantes do Sindicato dos professores, o PDE toma forma e se concretiza no ano de 2007, para produzir progressões na carreira e melhoria na qualidade da educação oferecida a milhares de crianças, jovens e adultos das escolas públicas do Paraná.

O Programa, que prevê avanços na carreira e tempo livre para estudos, demonstra a justa preocupação com a formação permanente dos educadores e com o real aprendizado de nossos estudantes. Esse programa de estudos tem duração de dois anos: no primeiro ano, o professor PDE é afastado de suas atividades em 100\% e, no segundo ano, em $25 \%$.

Esse novo modelo de Formação Continuada visa proporcionar ao professor PDE o retorno às atividades acadêmicas de sua área de formação inicial. Este é realizado, de forma presencial, nas Universidades públicas do Estado do Paraná, e, de forma semipresencial, em permanente contato do professor PDE com os demais professores da rede pública estadual de ensino, apoiados com os suportes tecnológicos necessários ao desenvolvimento da atividade colaborativa.

O professor PDE inicia suas atividades nesse novo processo de Formação Continuada elaborando um Plano de Trabalho em conjunto com o professor orientador das Instituições de Ensino Superior (IES). O Plano de Trabalho constitui uma proposta de intervenção na realidade escolar, a ser estruturada a partir de três grandes eixos: a proposta de estudo - que será desenvolvida ao longo de dois anos -, a elaboração de material (is) didático(s) - para uso nas escolas -, e a orientação de Grupo(s) de Trabalho em Rede - que envolve o conjunto dos professores da rede pública estadual.

Este programa, de caráter interinstitucional, envolve a Secretaria de Educação do Estado do Paraná (SEED), Secretaria da Ciência, Tecnologia e Ensino Superior (SETI), as cinco Instituições de Ensino Superior Estaduais Universidade Estadual de Londrina (UEL), Universidade Estadual de Maringá (UEM), Universidade Estadual do Centro-Oeste (UNICENTRO), Universidade do Oeste do Paraná (UNIOESTE) e Universidade Estadual de Ponta Grossa (UEPG) e as duas instituições federais Universidade Federal do Paraná (UFPR) e Universidade Tecnológica Federal do Paraná (UTFPR).

O PDE destina-se a atender 44.400 professores da rede estadual de ensino de forma indireta, por meio dos Grupos de Trabalho em Rede a cada ano e, diretamente, o programa atendeu 1.200 professores em 2007, 1.200 professores em 2008 e 2.400 professores em 2009, vagas essas distribuídas em dezessete áreas curriculares, a saber: Português, Matemática, Geografia, História, Ciências, Educação Física, Educação Artística, Física, Química, Biologia, Filosofia, Sociologia, Pedagogia, Línguas Estrangeiras Modernas, Educação e Trabalho, Gestão Escolar e Educação Especial. 
A proposta de formação continuada do Estado do Paraná para os professores, equipe pedagógica e equipe de gestão escolar enquadra-se no processo de educação corporativa ao preencher cada etapa.

\subsection{ETAPAS NO PROCESSO DE EDUCAÇÃO CORPORATIVA}

\subsubsection{Etapa 1 - Diagnóstico}

A proposta do programa surgiu após muitos estudos, análises dos índices de rendimento escolar dos alunos do Estado do Paraná frente às avaliações institucionais como a Prova Brasil, Exame Nacional do Ensino Médio (ENEM), Sistema de Avaliação da Educação Básica (SAEB) e os debates no interior das escolas públicas com os professores, equipes pedagógicas e direção que expuseram suas necessidades e anseios em relação à prática pedagógica.

Toda a análise organizacional levantou a necessidade de se proporcionar aos professores da rede pública estadual subsídios teórico-metodológicos para o desenvolvimento de ações educacionais sistematizadas, e que resultem em redimensionamento de sua prática e, consequentemente, na melhoria dos resultados.

\subsubsection{Etapa 2 - Planejamento}

\subsubsection{Elementos Constituintes do Programa}

Os elementos a seguir descrevem a estrutura de funcionamento do Programa, com base nos fundamentos já descritos, são eles: abrangência do programa e programa curricular.

\section{Abrangência do Programa}

Por sua natureza de programa interinstitucional, o PDE envolve a SEED, SETI, as cinco Instituições de Ensino Superiores Estaduais (UEL, UEM, UNICENTRO, UNIOESTE e UEPG) e as duas Instituições Federais (UFPR e UTFPR). 
O PDE destina-se a atender 44.400 professores da rede estadual de ensino de forma indireta, por meio dos Grupos de Trabalho em Rede, e, diretamente, 1.200 em 2007, 1.200 em 2008 e em 2009, 2.400 professores pertencentes ao Quadro Próprio do Magistério (QPM), Nível II, Classe 11, em pleno exercício de suas atividades, visando à sua promoção ao Nível III, conforme dispõe o Plano de Carreira dos Professores da Rede Pública de Ensino do Paraná.

Há um processo de seleção ao PDE que ocorre ao final de cada ano com o objetivo de suprir as vagas distribuídas em dezessete áreas curriculares. As vagas encontramse discriminadas no quadro a seguir e foram proporcionalmente distribuídas de acordo com o número de professores em serviço na rede pública estadual.

Quadro 1: Distribuição de vagas PDE para 2007

\begin{tabular}{|l|l|l|}
\hline $\begin{array}{l}\text { Número de áreas } \\
\text { atendidas }\end{array}$ & Áreas atendidas & $\begin{array}{l}\text { Número de vagas } \\
\text { por área atendida }\end{array}$ \\
\hline 01 & Português & 200 \\
\hline 02 & Matemática & 160 \\
\hline 03 & Geografia & 80 \\
\hline 04 & História & 110 \\
\hline 05 & Ciências & 80 \\
\hline 06 & Educação Física & 90 \\
\hline 07 & Educação Artística & 40 \\
\hline 08 & Física & 30 \\
\hline 09 & Química & 30 \\
\hline 10 & Biologia & 30 \\
\hline 11 & Filosofia & 10 \\
\hline 12 & Sociologia & 10 \\
\hline 13 & Pedagogia & 130 \\
\hline 14 & Línguas Estrangeiras Modernas & 80 \\
\hline 15 & Educação e Trabalho & 20 \\
\hline 16 & Gestão Escolar & 50 \\
\hline 17 & Educação Especial & 50 \\
\hline Total de Vagas & & 1200 \\
\hline & & \\
\hline
\end{tabular}

Fonte: Do autor 


\section{Programa Curricular}

O Programa Curricular ora apresentado toma como referência as Diretrizes Curriculares SEED e os Fundamentos Político-Pedagógicos do PDE. As atividades a serem desenvolvidas pelo Professor PDE compreendem: Aula Inaugural, Seminários, Cursos/Disciplinas, Elaboração e Execução do Plano de Trabalho, Coordenação de Grupos de Trabalho em Rede e Elaboração de Materiais Didáticos.

O Programa Curricular propõe um conjunto de conteúdos constantes nas Diretrizes Curriculares para a Educação Básica, os quais deverão ser desenvolvidos no âmbito do Programa a ser executado pelas Instituições de Ensino Superior - IES.

O Programa Curricular está dividido em dois grandes blocos de conteúdos, constituídos da seguinte forma:

a) bloco I - Fundamentos Político-Pedagógicos da SEED, cujas temáticas serão desenvolvidas pela Secretaria de Estado da Educação do Paraná por meio de Aula Inaugural e Seminário Geral;

b) bloco II-Conteúdos das Áreas Curriculares Específicas, que serão desenvolvidos nos Seminários Específicos, Cursos/Disciplinas e demais atividades pertinentes à execução do Plano de Trabalho dos professores PDE.

\subsubsection{Etapa 3 - Implementação}

O Programa de Desenvolvimento Educacional é desenvolvido por meio de Plano de Trabalho, no qual devem ser incorporadas as atividades básicas próprias do Programa, as quais abrangem os Seminários Centralizados, os Encontros Regionalizados do PDE e as Atividades de Formação e Integração em Rede. Por sua vez, as atividades específicas do Professor PDE são constituídas pela elaboração e execução do Plano de Trabalho, sob orientação das IES, com participação dos professores da Rede (Grupo de Trabalho em Rede), orientação aos Grupos dos Trabalhos em Rede e elaboração de material didático condizente com o objeto de estudo definido no Plano.

Quanto às atividades que são propostas pela Coordenação do PDE, faz-se importante ressaltar, a que se refere à elaboração do planejamento dos conteúdos a serem trabalhados nos Cursos ofertados nas IES. Essa atividade de planejamento curricular é realizada através de Seminário Centralizado.

Participam desse Seminário Integrado de Planejamento Curricular os professores orientadores das IES nas 17 (dezessete) áreas, os quais trabalham, em conjunto com as Equipes dos Departamentos específicos da SEED, com acompanhamento da Equipe do PDE. Essa ação, objetiva apoiar a integração entre as diferentes instâncias envolvidas no processo. 
Para melhor entendimento do sentido inovador do PDE, descreve-se, em suas linhas gerais, a estrutura básica a ser considerada para elaboração do Plano de Trabalho do Professor PDE. O plano de trabalho é um instrumento de orientação e planejamento de responsabilidade do professor PDE, de modo que deverá abarcar as atividades de estudo indicadas pelo professor orientador das IES, as atividades geradas pela proposta de intervenção na escola discutida no Grupo de Trabalho em Rede, bem como as etapas e fases do processo de elaboração do material didático, além da forma de orientação do Grupo de Trabalho em Rede.

Dessa forma, o professor PDE apresenta no espaço/tempo destinado aos Encontros de Orientação um pré-projeto do seu objeto de estudo/intervenção na realidade escolar ao professor orientador, discutindo os seus encaminhamentos teórico-práticos, que pode ser traduzido no roteiro abaixo:
a) problematização;
b) definição do objeto de estudo;
c) fundamentação teórica;
d) desenvolvimento metodológico (atividades e material didático a ser produzido);
e) cronograma de atividades;
f) referências.

A proposta de intervenção constante do Plano é efetivada a partir do terceiro e quarto períodos do Programa. Seu desenvolvimento e resultados são tomados como critérios de avaliação final do professor PDE. Assim, os componentes da proposta de intervenção, são:

a) Estudos orientados - compreendido como momento de formação/ fundamentação por excelência, durante o qual são realizados os encontros de orientação, os encontros das áreas específicas do PDE, os Seminários e Cursos Descentralizados da SEED nas IES e a Orientação dos Grupos de Trabalho em Rede.

b) Elaboração de material didático - o professor PDE, com o devido acompanhamento de seu orientador e a colaboração dos Grupos de Trabalho em Rede, deve produzir material didático-pedagógico pertinente ao seu objeto de estudo e articulado aos projetos que vêm sendo executados no âmbito da SEED/Educação Básica. Indica-se a elaboração de um Objeto de Aprendizagem Colaborativa (OAC), um Projeto Folhas, processo de formação continuada dos professores, por meio da produção colaborativa de textos de conteúdos pedagógicos, que constituirão material didático para os alunos e apoio ao trabalho docente, e um Artigo Científico propositivo. O OAC destina-se a 
fundamentar o trabalho dos professores e o Projeto Folhas, de caráter didático, pode ser utilizado como material de apoio para o trabalho com os alunos. Essas produções têm como foco os conteúdos disciplinares previstos para a Rede Pública Estadual. O PDE estimula, igualmente, a produção de diferentes formas de materiais didáticos, desde que guardem relação com as ações já em curso no âmbito da SEED, como, por exemplo, produção de roteiros e programas para televisão (TV Educativa e TV Paulo Freire), vídeos com aulas ou documentários para inserção na TV Paulo Freire e materiais impressos, como livros e mapas, para utilização dentro ou fora das salas de aula, dentre outras. São válidas também produções conjuntas relacionadas aos Projetos Educação Com Ciência, Festival de Arte da Rede Estudantil - Fera e Jogos Colegiais.

c) Orientação de Grupos de Trabalho em Rede - essa atividade configura- se com importante estratégia de democratização do conhecimento. É por meio dela que o professor PDE socializa os conhecimentos apreendidos, desde o início do Programa, para os demais professores da rede pública estadual, considerando as suas áreas curriculares específicas de atuação.

Dessa forma, cada professor PDE desempenha a função de Orientador de Grupo de Trabalho em Rede, com previsão de atendimento a, no máximo, 37 (trinta e sete), professores da Rede. Essa atividade é realizada utilizando os recursos tecnológicos da educação à distância.

O professor que ingressa no PDE desenvolve um conjunto de atividades num prazo de até dois anos, perfazendo um total de até 952 (novecentos e cinquenta e duas horas). Também exerce a atividade de orientação de um grupo de professores da rede. Desse modo, o conjunto dos professores em exercício é contemplado pelo Programa e se integra ao Plano de Trabalho do professor PDE.

\subsubsection{Etapa 4 - Avaliação}

O processo de avaliação deve servir para analisar, compreender, desvelar, descobrir, pesquisar, estabelecer correlações, ampliar a visão de mundo do indivíduo, aprofundar questões, dialogar, construir significados de aprendizagem para os sujeitos e para a coletividade.

Nessa perspectiva, considera-se fundamental que os princípios pedagógicos apontados pelo Programa encontrem ressonância direta nos processos avaliativos dos professores participantes do PDE. Assim, a avaliação da aprendizagem dos professores é considerada nos Planos de Trabalho dos professores PDE durante o desenvolvimento das atividades, culminando com a Certificação dos Professores PDE. 
Por outro lado, a avaliação institucional do Programa é garantida pela permanente integração de atividades de Coordenação já consideradas durante o processo de institucionalização do Programa entre SEED, SETI e IES.

Um terceiro momento dessa avaliação ocorre no momento em que os alunos da rede pública do Estado do Paraná começam a demonstrar o ganho pedagógico com o enriquecimento das práticas de seus professores, professores pedagogos e de seus diretores.

\title{
3 CONSIDERAÇÕES FINAIS
}

A formação continuada apresenta em sua essência aspectos profissionais como a formação, a profissão, a avaliação e as competências que cabem ao profissional. Todo profissional deve buscar sempre uma formação contínua e também ampliar seu campo de trabalho, evoluir profissionalmente.

Neste sentido, a gestão de Capital Humano, seja de uma organização de cunho privado, seja pública, pode e deve fomentar em seus colaboradores a busca por esse crescimento que transborda do campo profissional para o pessoal. Pessoas melhores, mais preparadas para a vida resultam em melhores profissionais.

A tendência de gestão do capital humano por meio da formação continuada se faz presente de forma tão expressiva que todas as esferas organizacionais podem apropriarse de seus fundamentos.

Setores públicos e privados, cada um com suas peculiaridades corporativas, tendem a fazer uso dessa ferramenta que surge no mercado de trabalho com o intuito de otimizar os serviços ofertados à sociedade como um todo.

\section{CONTINUING EDUCATION: FOUNDATION OF HUMAN CAPITAL MANAGEMENT IN PUBLIC PERSPECTIVE}

\begin{abstract}
This article aims to present a public experience in the sector of human capital management through continuing education in the field of education in order to demonstrate the concern of the state with the training of its employees and also prove that the public sector also has means of implementing a corporate education. The program presented here was designed and was implemented by the Education Department of the State
\end{abstract}


of Paraná in order to provide to the teacher of basic education of public school the theoretical and methodological support for resizing their educational practice. The proposed study was conducted by reading official documents.

Keywords: Continuing Education. Human capital management. State of Paraná

\section{REFERÊNCIA}

MUNDIM, Ana Paula Freitas. Desenvolvimento de produtos e educação Corporativa. 1.ed. São Paulo: Atlas, 2002.

\section{BIBLIOGRAFIAS}

DUTRA, Ademar; OLIVEIRA, Marcos Aurélio Travassos de; LÜCKMANN, Jehan Carla Zunino. Gestão Estratégica do Capital Humano. Florianópolis: CNI/SENAI, 2009.

GIANNETTI, Eduardo. Vícios privados, benefícios públicos?: a ética na riqueza das nações. São Paulo: Cia. das Letras, 1993.

PARANÁ (Estado). Lei complementar n 103, de 15 de março de 2004. Diário Oficial no 6687 de 15 de março de 2004. Disponível em: <http://celepar7cta.pr.gov.br/SEEG/ sumulas.nsf/319b106715f69a4b03256efc00601826/0136dea4d1af589c03256e98006e 2e8b>. Acesso em: 13 jun. 2013.

PARANÁ (Estado). Secretaria de Estado da Educação. Uma nova política de formação continuada e valorização do professor da educação básica da rede pública estadual: documento síntese. Curitiba, 2007. 


\section{SOBRE O AUTOR}

\begin{tabular}{||l||l||}
\hline $\begin{array}{l}\text { Graduado em Tecnologia Mecânica (UTFPR), Graduado em Pedagogia para } \\
\text { Formadores em Educação Profissional (UNISUL), Mestre em Engenharia } \\
\text { Mecânica (UERJ), Pós-Graduado em Gestão Industrial (SENAI-SC), Pós- } \\
\text { Graduado em Consultoria Empresarial (SENAI-SC), Técnico Mecânico (CEFET- } \\
\text { PR). Docente no programa de Pos Graduação nos cursos Engenharia de } \\
\text { Manutenção Industrial (SENAI-SC), MBA Gestão Industrial (SENAI-SC) e em } \\
\text { Lean Manufacturing (SENAI-SC). No SENAI-PR atua como consultor técnico e } \\
\text { instrutor nas áreas ligadas a Metal Mecânico: implantação de manutenção } \\
\text { preventiva, TPM, PCM, layout, melhoria de processos (solda, usinagem, } \\
\text { estampagem, conformação mecânica, caldeiraria, serralheria, automação), } \\
\text { inspetor de solda para qualificação de procedimentos e soldadores, } \\
\text { como docente nos cursos técnico-tecnológicos atua nas modalidades de: } \\
\text { metrologia, elementos de máquinas, resistência dos materiais, desenho } \\
\text { técnico, manutenção industrial, projetos, pneumática e hidráulica. }\end{array}$ \\
\hline
\end{tabular}

